\title{
Spatial interpolation techniques for a near real-time mapping of Pressure and Temperature data
}

\author{
llaria Ferrando ${ }^{1}$, Pierluigi De Rosa ${ }^{2}$, Bianca Federici ${ }^{1}$, and Domenico \\ Sguerso ${ }^{1}$ \\ ${ }^{1}$ Laboratory of Geomatics, Geodesy and GIS, Department of Civil, Chemical and \\ Environmental Engineering, University of Genoa, Italy \\ ${ }^{2}$ Department of Physics and Geology, University of Perugia, Italy - Via Faina, 4 - \\ Perugia, Italy 06100
}

\begin{abstract}
Among the different techniques for atmosphere monitoring, the GNSS (Global Navigation Satellite System) can provide an innovative contribution (Bevis et al., 1992; Crespi et al., 2004; Sguerso et al., 2013, 2015). The Laboratory of Geomatics, Geodesy and GIS of the University of Genoa has identified a GIS procedure and a simplified physical model to monitor the Precipitable Water Vapour (PWV) content, using data measured by existing infrastructures. The starting points are local estimations of Zenith Total Delay (ZTD) from a GNSS Permanent Stations (PSs) network, a Digital Terrain Model (DTM) and local Pressure (P) and Temperature (T) measurements (Sguerso et al., 2014; Ferrando et al., 2016). The present paper shows the study of the most appropriate interpolation technique for $\mathrm{P}$ and $\mathrm{T}$ data to create PWV maps in a quick, stable and automatic way, to support the monitoring of intense meteorological events for both a posteriori and near real-time applications. The resulting $\mathrm{P}$ and $\mathrm{T}$ maps were compared to meteorological re-analysis, to check the reliability of the simplified physical model. Additionally, the Regression Kriging (RK) was employed to evaluate the data correlation with elevation and to study the applicability of the technique.
\end{abstract}

Keywords: Environmental data interpolation, Meteorological re-analysis, Regression kriging

\section{INTRODUCTION}

To understand the role of Precipitable Water Vapour (PWV) in monitoring severe meteorological events, 2D distribution of $\mathrm{P}$ and $\mathrm{T}$ has to be produced starting from local observations: this is made possible by means of data interpolation and a simplified physical model, owned by the Laboratory of Geomatics, Geodesy and GIS (Sguerso et al., 2014; Ferrando et al., 2016), already applied in few test cases.

The choice of the most appropriate interpolation technique, according to the spatial distribution of data, is surely a key issue. Different interpolation techniques were employed, in order to find the most suitable for automatic and fast interpolation. Additionally, the interpolated $\mathrm{P}$ and $\mathrm{T}$ maps were compared with $\mathrm{P}$ and $\mathrm{T}$ fields coming from re-analysis, produced by meteorological model analysing past events using the whole set of measured meteorological data. The case study is the severe meteorological event occurred on $4^{\text {th }}$ November 2011 in Genoa (Italy).

The adequacy of the interpolation technique to reproduce $\mathrm{P}$ and $\mathrm{T}$ fields is treated in the first two sections. The final section is dedicated to the geostatistical interpolation of data by means of Regression Kriging (RK).

\section{DATA AND DETERMINISTIC INTERPOLATION TECHNIQUES}

53 Pressure and 58 Temperature NOAA meteorological stations (www.noaa.gov) were used for the interpolation. Figure 1 shows the spatial distribution of $\mathrm{P}$ (circles) and $\mathrm{T}$ (crosses) stations, covering approximately north-west of Italy and the French-Italian border region, with a mean spacing of 150 
km. 4 stations, called "checkpoints" and displayed in figure 1 as small triangles, were excluded in the interpolation and used to verify the accordance between interpolated and re-analysed fields.

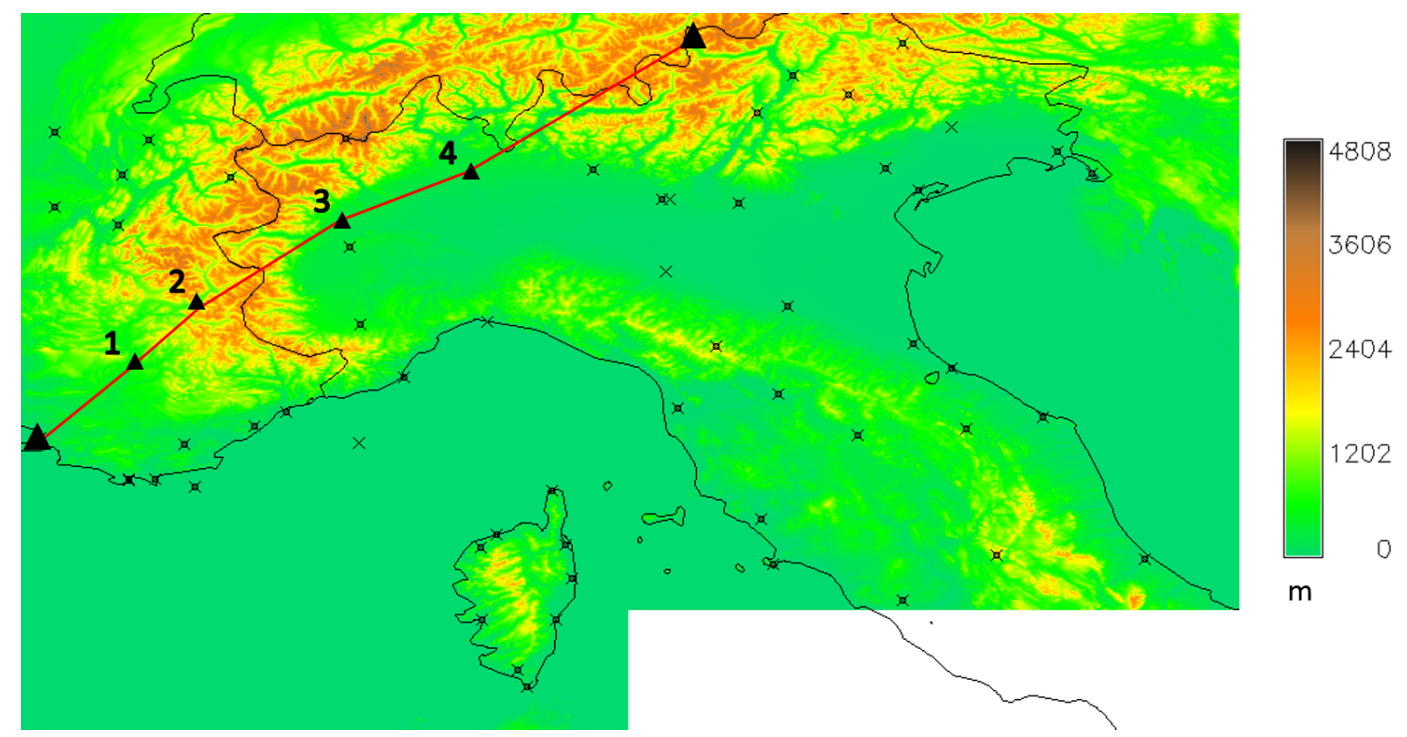

Figure 1. Distribution of $\mathrm{P}$ (circles) and $\mathrm{T}$ (crosses) stations. The transept crossing the checkpoints (small triangles) is displayed in red.

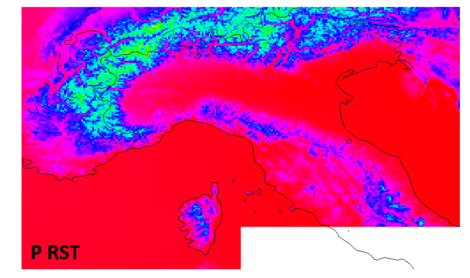

The interpolation was carried out at a resolution of about $3.5 \mathrm{~km}$, accordingly to the one used for re-analysis. The 2D maps obtained by Inverse Distance Weighted (IDW), Regularized Spline with Tension (RST) and Triangulated Irregular Network (TIN) techniques for P and T are shown in figure 2, on top and bottom respectively.
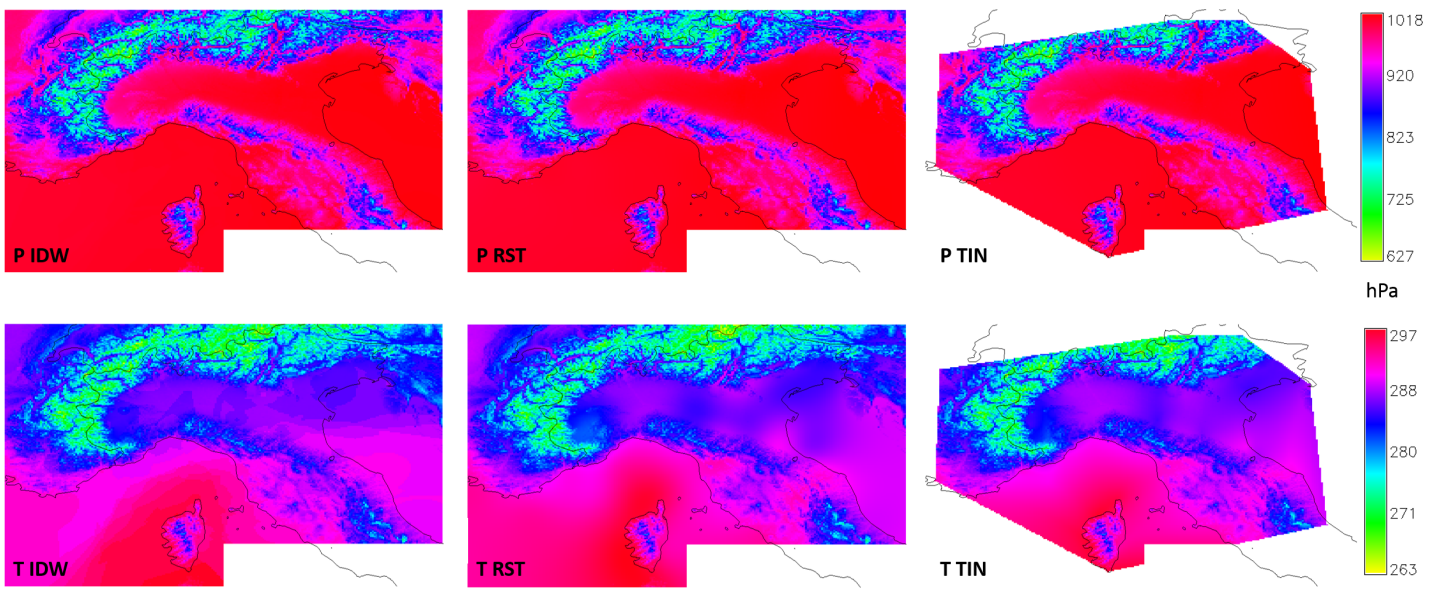

$\mathrm{hPa}$

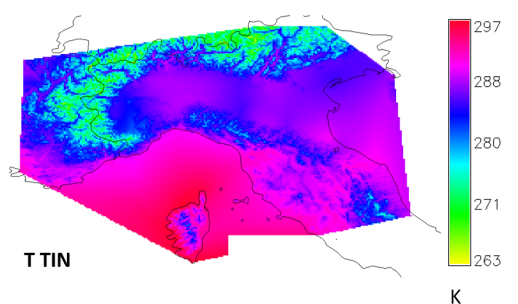

Figure 2. $\mathrm{P}$ (top) and T (bottom) fields obtained using IDW, RST and TIN interpolation techniques.

\section{COMPARISON WITH RE-ANALYSIS}

Two different comparisons were carried out for the interpolated maps obtained in the previous section: along the transept to locally check the adherence with the re-analysis and measured data, and 2D differences maps between the re-analysis and the interpolated fields to evaluate the global behaviour in the study area. 
1D comparison: behaviour along the transept

The transept passes across 4 meteorological station (the checkpoints). Figure 3 shows the values along the transept of $\mathrm{P}$ and T respectively, for IDW, RST, TIN, re-analysis and NOAA observed data.

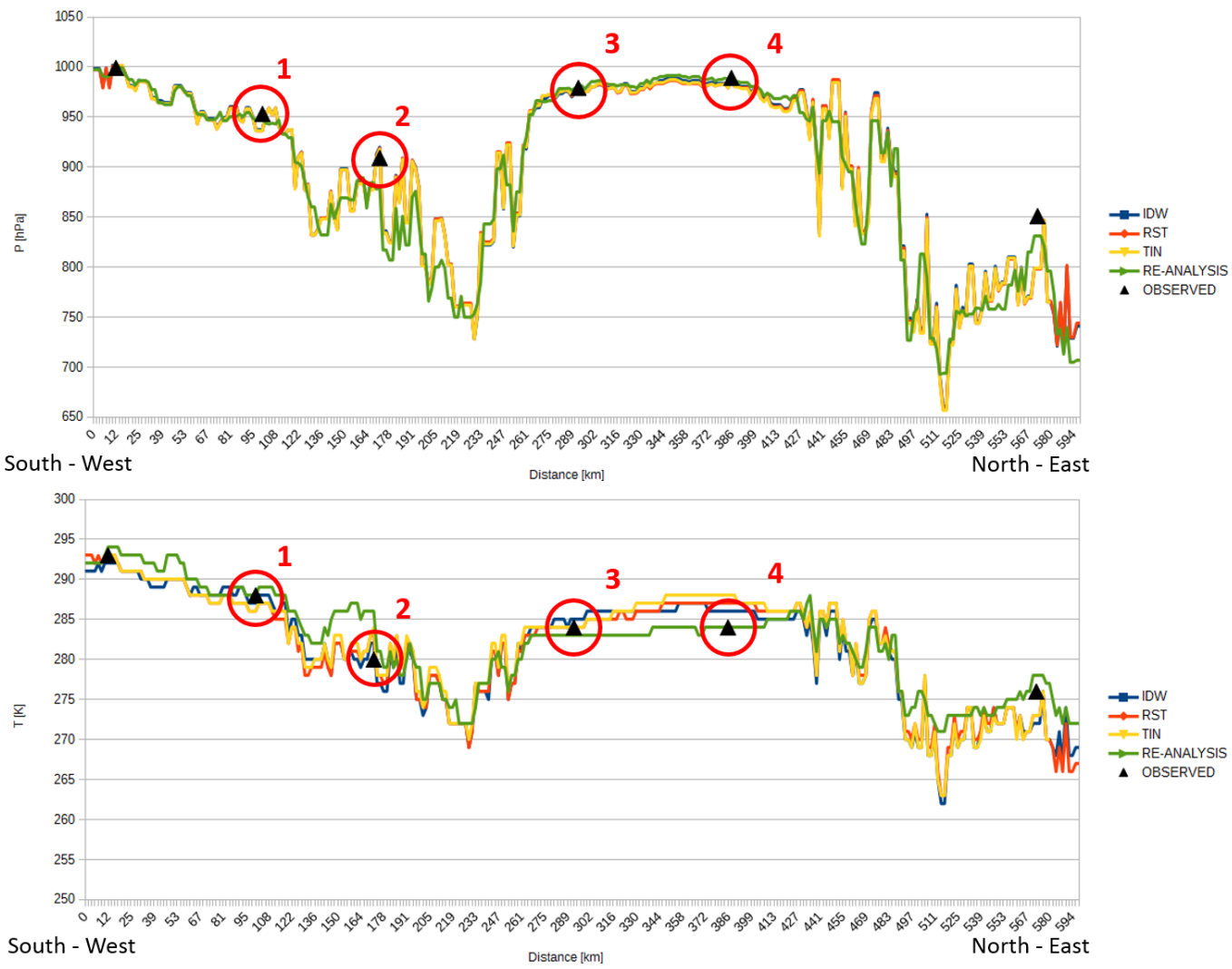

Figure 3. P (top) and T (bottom) values along the transept.

The interpolated maps seem quite similar along the transept. The accordance between re-analysis, observed data and interpolated fields is good, in the checkpoints too, showing that it is possible to obtain $\mathrm{P}$ and $\mathrm{T}$ fields even from sparse data. The major differences occur in high altitude areas, probably due to the generalization of the adopted model. P seems to be more complying to re-analysis and observed data than T. Focusing on the checkpoints, the maximum difference between re-analysis and interpolated fields are around $40 \mathrm{hPa}$ in checkpoint 2 for all the applied techniques, and $4 \mathrm{~K}$ for checkpoint 4 for TIN. It should be noted that on checkpoint 2 there is a disagreement between re-analysis and $\mathrm{P}$ observed data, this is maybe the cause of the previously mentioned high differences. Finally, high differences can be noticed on the edge regions, due to the different behaviours of the interpolation techniques.

\section{D comparison: difference maps}

The higher differences are located in high altitude areas, both for P (top of figure 4) and T (bottom of figure 4) and in the edge regions, confirming what previously noted along the transept.

Especially in T maps, differences due to the patterns of interpolators can be seen. These differences are in the order of few K, thus they are not considered influential in the description of the field. Differently, as shown in the top of figure 4 , not negligible differences $(\max =66 \mathrm{hPa}$; $\min =-85 \mathrm{hPa}$ ) are present in $\mathrm{P}$ field around Genoa. This could be caused by the generalization of the simplified model, not capable to describe local strong variations and to the absence of $\mathrm{P}$ data in the area. As already noted (Ferrando et al., 2016), the presence of these differences don't influence the interpretation of PWV and its evolution in time, thus the procedure is considered reliable for severe meteorological events monitoring. Again, the global behaviour of the different interpolators seems to be similar, except for the already mentioned pattern, typical of each technique. 

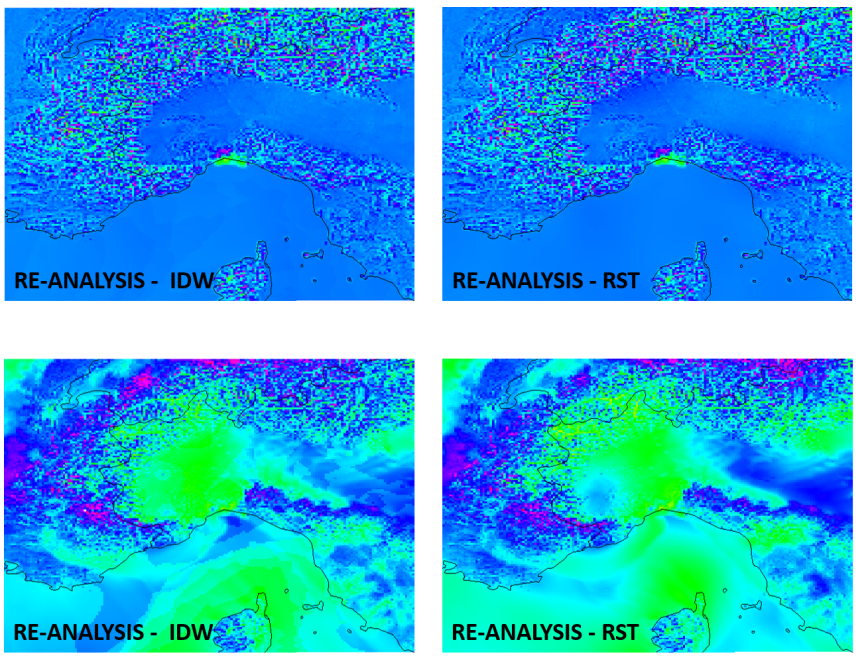
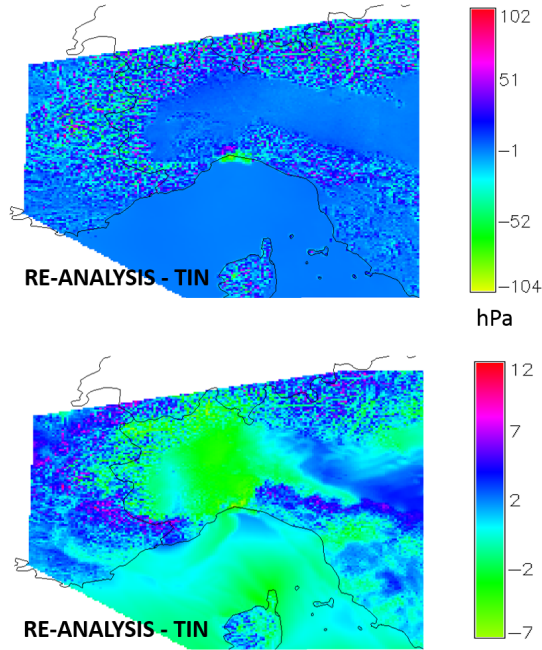

Figure 4. $\mathrm{P}$ (top) and $\mathrm{T}$ (bottom) differences.

Considering the application of this procedure in near real-time, the interpolator should be fast and automatically adjustable to the different network configurations that may change in time. For this reason, TIN interpolator, available as GRASS add-on by means of $r$.surf.nnbathy module (Sieczka and GRASS Development Team, 2006; GRASS Development Team, 2016), was chosen to produce PWV maps, for its adaptability and for not needing to calibrate additional parameters.

In the next section, a geostatistical analysis for $\mathrm{P}$ and $\mathrm{T}$ data is performed.

\section{GEOSTATISTICAL INTERPOLATION}

$\mathrm{P}$ and $\mathrm{T}$ data show a strong correlation with elevation as figure 5 shows. For such reason, the Regression Kriging (RK) (Hengl et al., 2007) could be the best interpolation technique as it is able to use elevation information as base data for interpolate Pressure and Temperature values. The ASTER GDEM digital elevation model has been used as raster layer providing the auxiliary variable in order to interpolate the regression residuals.
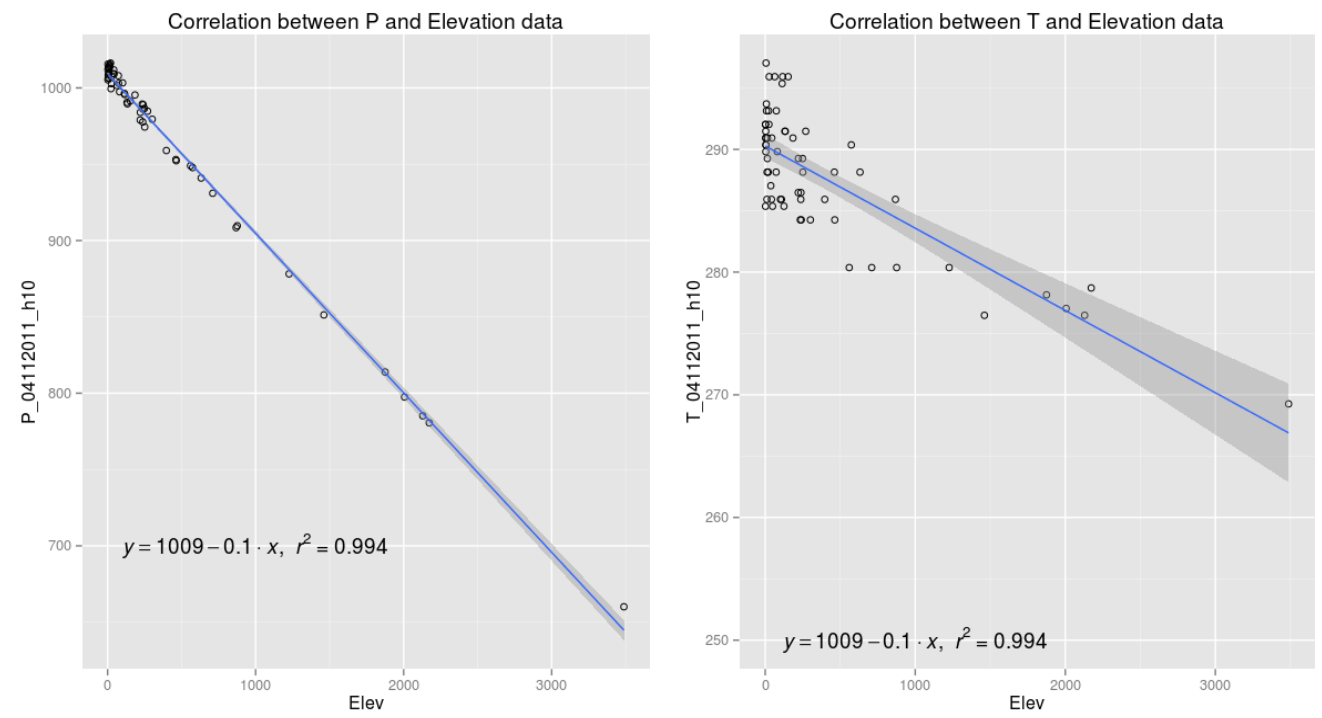

Figure 5. Correlation between $\mathrm{P}$ and $\mathrm{T}$ values versus elevation data. 
The goodness of the RK analysis could be observed in figure 6: on the left, the bubbles of the cross validation procedure of IDW, using $5 \mathrm{k}$-folds; on the right, the bubble plot of RK interpolation. It turns out how the IDW has a range of errors much wider than RK, also the location of residuals error is not similar in both cases: IDW shows biggest errors in Alpine and in Apennines regions, whereas RK shows the biggest residual errors only in Alpine region.

IDW Cross-validation errors

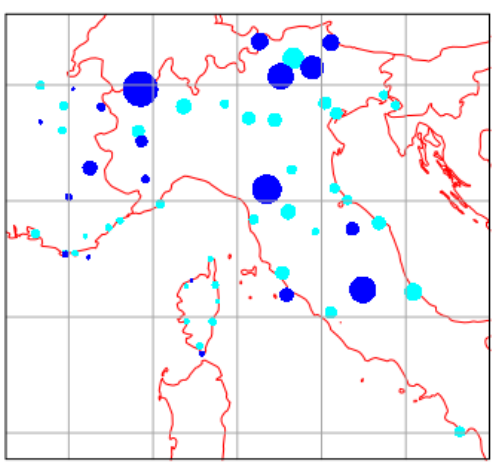

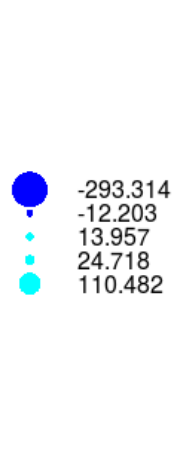

RK Cross-validation errors

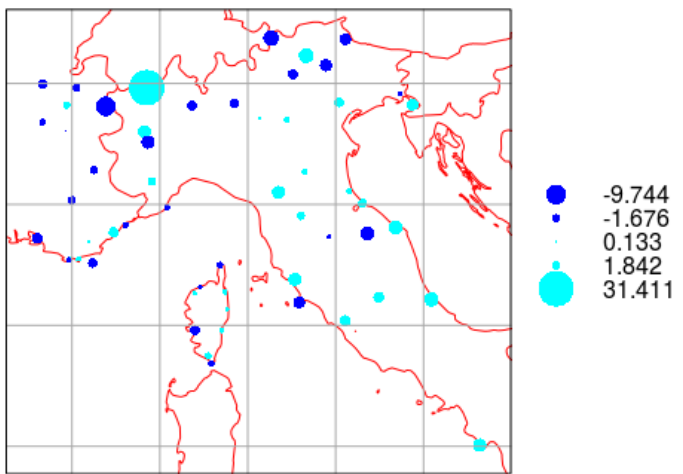

Figure 6. Bubble plots comparing the IDW (left) and RK interpolation methods (right) using a 5 k-folds cross validation procedure.

The RK interpolation has been implemented into R statistical software (R Core Team, 2016) using gstat and intamap packages (Pebesma, 2004; Pebesma et al., 2010). In particular, a R code has been produced to run the procedure automatically. The code is able to load $\mathrm{P}$ and $\mathrm{T}$ data, execute the variogram analysis of the dependent variables on auxiliary variables (elevation from ASTER GDEM) and compute the interpolated raster for $\mathrm{P}$ and $\mathrm{T}$ and relative map of kriging errors.

\section{CONCLUSIONS AND FUTURE DEVELOPMENTS}

A deep analysis of the different interpolation techniques was carried out, in order to find the most appropriate for near real-time applications too. Despite the difficulties due to the sparse distribution of $\mathrm{P}$ and $\mathrm{T}$ data and the considerable orographic effect, the simplified physical model implemented by the Laboratory of Geomatics, Geodesy and GIS is reliable to produce 2D PWV maps with good adherence to re-analysis. The geostatistical analysis of data helped in analysing the correlation between data and elevation, computing the interpolated maps and evaluating the errors. The comparison between $\mathrm{P}$ and $\mathrm{T}$ Kriging maps, the deterministic interpolated maps and the re-analysis will be carried out in the future complete paper.

\section{ACKNOWLEDGMENTS}

Thanks to Federico Cassola and PM_TEN srl (DIFI, Department of Physics, spin-off of University of Genoa) and to Andrea Mazzino (DICCA, Department of Civil, Chemical and Environmental Engineering, University of Genoa) for sharing the re-analysis data.

\section{REFERENCES}

Bevis, M., Businger, S., Herring, T. A., Rocken, C., Anthes, R. A., and Ware, R. H. (1992). Gps meteorology: Remote sensing of atmospheric water vapor using the global positioning system. Journal of Geophysical Research: Atmospheres, 97(D14):15787-15801.

Crespi, M., Luzietti, L., Frattale Mascioli, F. M., and Rizzi, A. (2004). Impiego meteorologico del gps per la previsione di precipitazioni critiche. In Atti della 8 Conferenza Nazionale ASITA. ASITA.

Ferrando, I., Federici, B., and Sguerso, D. (2016). Environmental data interpolation to support GNSS monitoring of potential precipitation. Geomatics Workbooks, 13. (accepted for publication, under revision). 
GRASS Development Team (2016). Geographic Resources Analysis Support System (GRASS GIS) Software, Version 7.0. Open Source Geospatial Foundation.

Hengl, T., Heuvelink, G. B., and Rossiter, D. G. (2007). About regression-kriging: from equations to case studies. Computers \& Geosciences, 33(10):1301-1315.

Pebesma, E., Cornford, D., Dubois, G., Heuvelink, G., Hristopoulos, D., Pilz, J., Stoehlker, U., Morin, G., and Skoien, J. (2010). Intamap: the design and implementation of an interoperable automated interpolation web service. Computers \& Geosciences, 37:343-352.

Pebesma, E. J. (2004). Multivariable geostatistics in s: the gstat package. Computers \& Geosciences, 30:683-691.

R Core Team (2016). R: A Language and Environment for Statistical Computing. R Foundation for Statistical Computing, Vienna, Austria.

Sguerso, D., Federici, B., Agrillo, G., and Ferrando, I. (2014). Il contributo della geomatica alla valutazione delle allerte meteorologiche. Newton's Bulletin, Vol. Il prof. Sansò e l'evoluzione della geodesia in Italia, CD-ROM:1-11.

Sguerso, D., Labbouz, L., and Walpersdorf, A. (2013). 14 years of gps tropospheric delays in the frenchitalian border region: a data base for meteorological and climatological analyses. In International Workshop "The Role of Geomatics in Hydrogeological Risk".

Sguerso, D., Labbouz, L., and Walpersdorf, A. (2015). 14 years of gps tropospheric delays in the french-italian border region: comparisons and first application in a case study. Applied Geomatics, 8(1):13-25.

Sieczka, M. and GRASS Development Team (2006). r.surf.nnbathy GRASS Software, Version 6.4.. Open Source Geospatial Foundation. 